\title{
Review and Survey of Broadband Microstrip Patch Antennas
}

\author{
Ajay Singh \\ Dehradun Institute of Technology \\ Dehradun (India)
}

\author{
S. C. Gupta \\ Dehradun Institute of Technology \\ Dehradun (India)
}

\begin{abstract}
Microstrip Patch Antenna (MPA) is generally used in modern communication devices, and a large part of day-to-day communication is done through it. Study of literature of past few year shows that, the leading work on MPA is focused on designing compact sized broadband microstrip antenna. But inherently MPA have narrow bandwidth so to enhance bandwidth various techniques are engaged. This review paper demonstrates some commonly engaged techniques to fabricate MPA with broader-bandwidth since last few decades.
\end{abstract}

\section{INTRODUCTION}

Microstrip Patch Antenna (MPA) is commonly used because of its low profile, low cost and ease of manufacturing. A patch antenna is made by etching metal on one side of dielectric substrate where as on the opposite side there is continuous metal layer of the substrate which forms a ground plane [1]. MPAs are inherently a narrowband antennas so; various bandwidth enhancement techniques are engaged while keeping its size as compact as possible to be perfectly used as a low profile antenna. Due to which many studies and researches are being done throughout the globe.

Practically bandwidth of MPA is narrow but, today wireless communication systems require higher operating bandwidth. Such as about $7.6 \%$ for a global system for mobile communication (GSM; 890-960 MHz), $9.5 \%$ for a digital communication system (DCS; $1710-1880 \mathrm{MHz}$ ), $7.5 \%$ for a personal communication system (PCS; $1850-1990 \mathrm{MHz}$ ), and $12.2 \%$ for a universal mobile telecommunication system (UMTS; 1920-2170 MHz) [2]. To achieve these required bandwidths many techniques are used and some of them are given explained further in review this paper.

\section{BANDWIDTH ENANCWMENT TECHNIQUES USED FOR MICROSTRIP PATCH ANTENNAS}

The major need for today's communication devices is to operate at broader band such as to support high speed internet, multimedia communication and similarly many more broadband services, this is achieved by using microstrip patch antennas, but inherently microstrip antennas are narrow band antennas so, various techniques are used to enhance the bandwidth of microstrip antenna. In this section bandwidth enhancement or broadband techniques are explained. Modified shape patch, Planar Multiresonator configuration, Multilayered configuration and Stacked Multiresonator microstrip patch antenna are mainly used for broadband microstrip antenna.

\subsection{Modified Shape Patch Broadband Microstrip Patch Antenna}

In this technique bandwidth enhancement is done by changing/modifying the shape of radiating patch. It is found that some shapes of patches have lower Q factor as compared to other therefore having high bandwidth [5]. These patches shapes include annular ring, rectangular/square ring, shorted patch and other geometries. There are several designs of broadband microstrip patch antenna with modified patches. A design of broadband circular patch microstrip antenna with Diamond shape slot is given by Garima, et al. [6]. In this paper a circular patch microstrip antenna having a concentric diamond shape slot is presented. Its configuration is shown in figure (1).

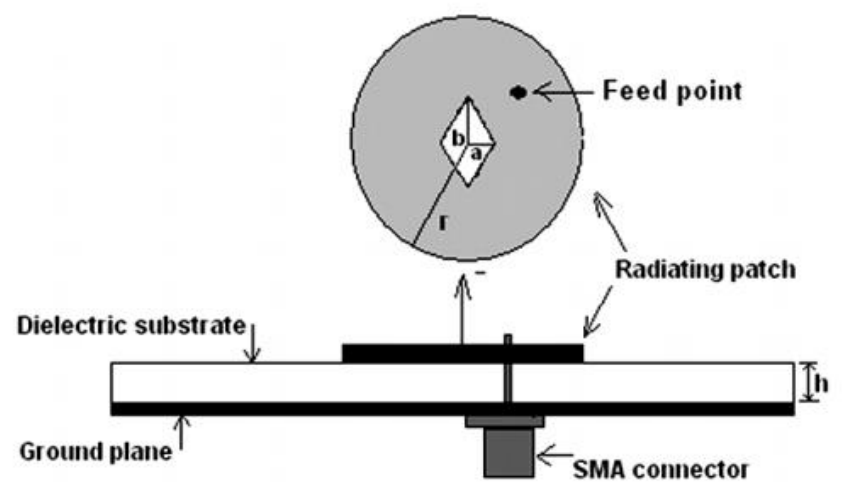

Fig 1: Circular patch geometry with concentric diamond slot [6]. 
This antenna is applicable for C-band. Substrate used in this antenna is FR-4 and produces the bandwidth of $13.58 \%$ when compared with conventional circular patch antenna. Gain of proposed antenna is almost constant in the frequency range where broadband operation is realized. The performance of proposed antenna is improved when compared with that of conventional circular patch antenna having identical radius.

Another design for modified shape patch is T-slot Broadband Rectangular Patch Antenna shown in figure (2) is

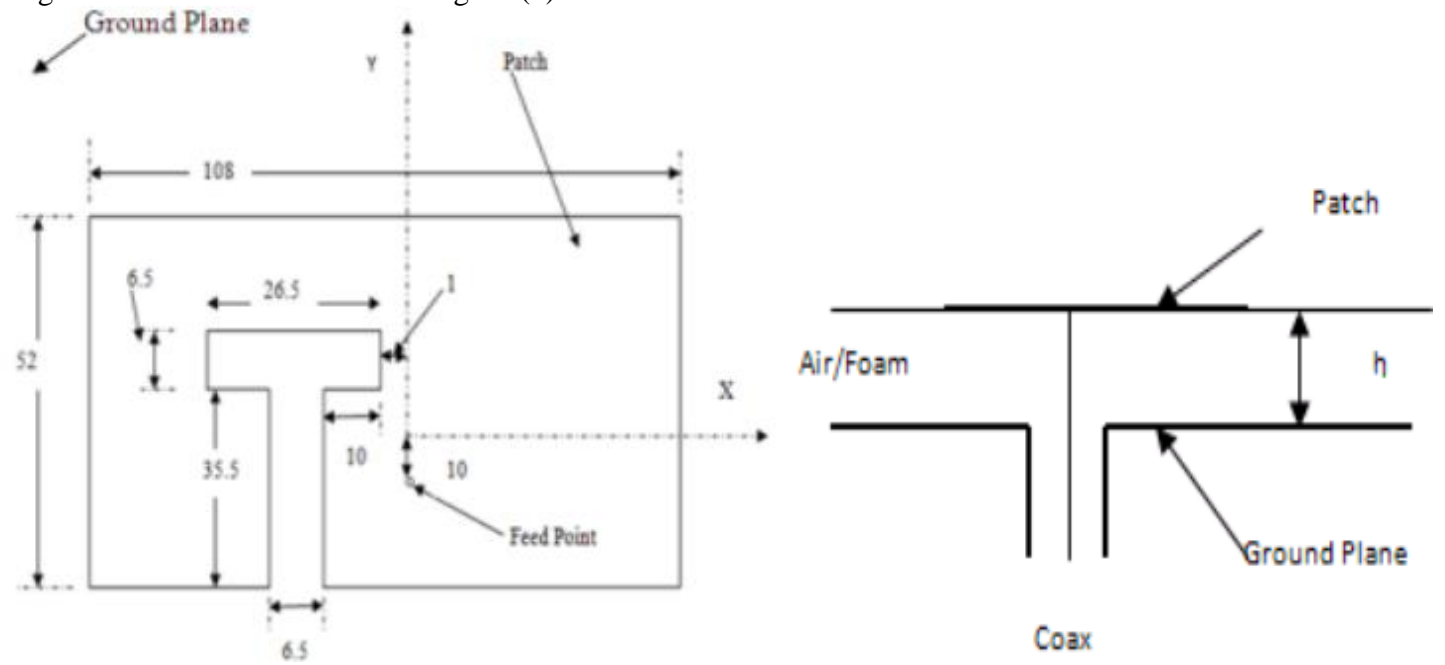

Fig 2: Top and side view of modified T-shaped patch (dimensions of top view are in mm) [7].

A design with Single-layer single-patch wideband microstrip antenna is given by T. Huynh and K. F. Lee [8] which is shown in figure (3). In this paper a radiating patch with U-shaped slot of microstrip antenna is given. Enhanced given by Lolit Kumar Singh, et al. [7]. In this paper a single layer single probe fed T-slot broadband rectangular patch antenna is proposed. Impedance bandwidth of $25.23 \%$ with an average gain of about $7.43 \mathrm{dBi}$ over the entire passband and peak gain of $9.88 \mathrm{dBi}$ at $-10 \mathrm{~dB}$ return loss is achieved. Simulation is done by using air substrate $\left(\varepsilon_{\mathrm{r}}=1\right)$ and for practical purpose foam is used for support.

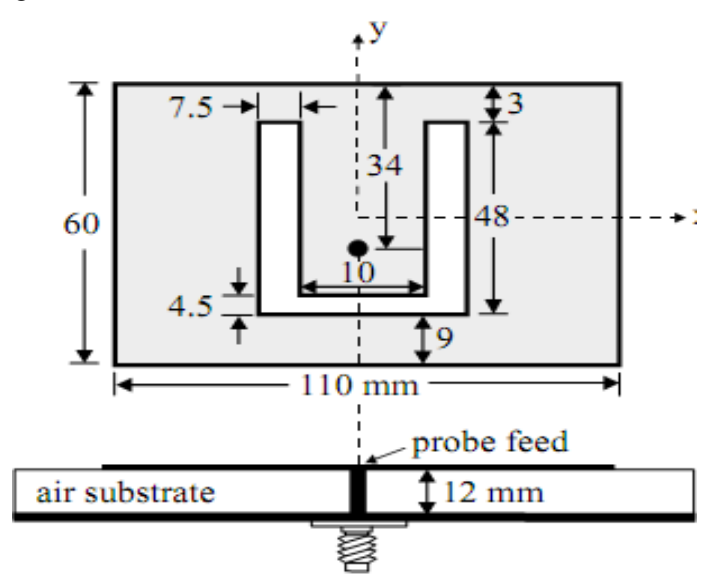

Fig 3: A broadband probe-fed rectangular microstrip antenna with a U-shaped slot [8].

One more method of achieving broadband microstrip patch antenna is Modified E-H Shaped patch antenna [9] as shown in figure (4), it is purposed by Mohammad Tariqul Islam et al., an L-probe fed microstrip patch antenna with low cross-polarization and modified E-H shaped patch design is proposed to operate at 1.79 to 2.34 bandwidth is achieved by the U-shaped slot with a thick air substrate of $12 \mathrm{~mm}$ and the impedance bandwidth of $500 \mathrm{MHz}$ or $27.5 \%$ is achieved at the centre frequency $1815 \mathrm{MHz}$ (at 10 $\mathrm{dB}$ return loss). 

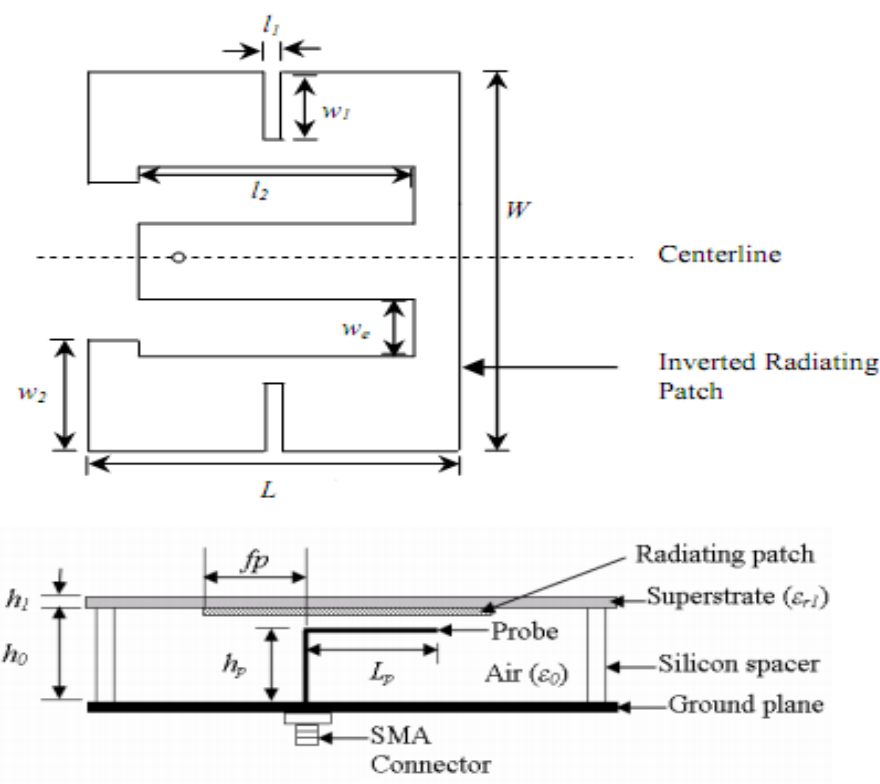

Fig 4: Geometry of proposed antenna with top and side view [9].

\subsection{Planar Multiresonator configuration of Broadband Microstrip Patch Antenna}

In such configuration of microstrip antenna multiple resonators are placed near to each other, only one is fed and others are parasitically coupled, it is also known as gap coupling. Another way used to feed multiresonator configuration is to directly connect the patches via microstrip line. In some cases hybrid coupling is also used which include gap and direct coupling [10]. Design of Bandwidth Enhancement of Microstrip Antennas Using Shifted

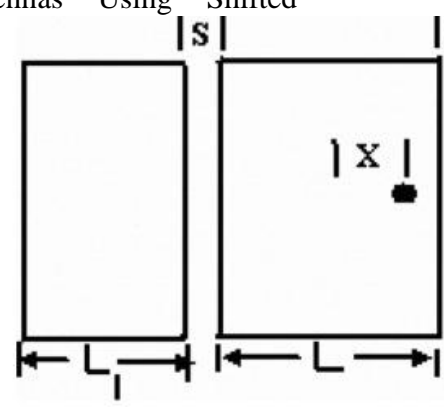

Fig 5: Multiresonator gap coupled patches [11].

Configuration of multiresonator broadband microstrip patch antenna [12] is shown in figure (6). Here gap-coupled planar multi-resonator and stacked configurations are combined to obtain wide bandwidth with

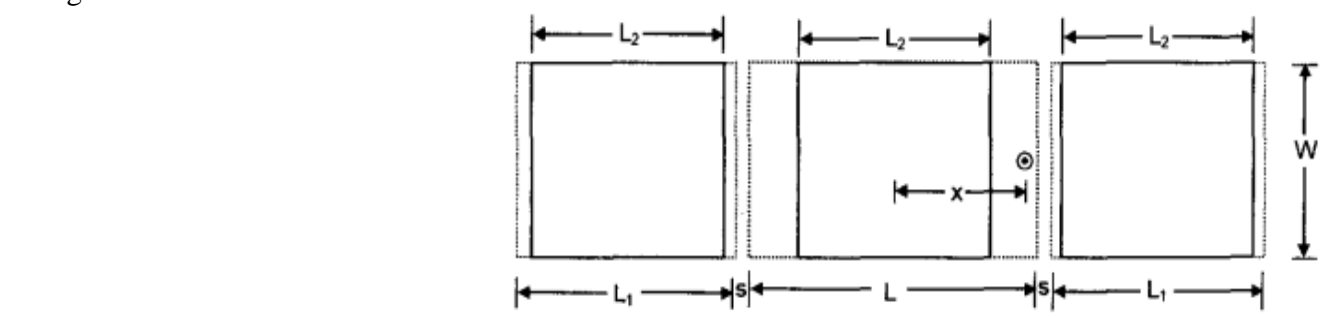

Fig 6: Gap-coupled multi-resonator patches [12].

A proposed broadband microstrip antenna with directly coupled and parasitic patches has been constructed
Parasitically Coupled Planar Multiresonators is given by K. Chattopadhyay et al. [11]. Proposed design is shown below in figure (5). In this paper, a wideband planar multi resonator antenna with parasitic coupling is proposed. Results show gradual improvement in impedance bandwidth from $65 \mathrm{MHz}$ to $251 \mathrm{MHz}$ (about four times) with very minor variation of resonance frequency from $2.989 \mathrm{GHz}$ for reference patch to $3.023 \mathrm{GHz}$ for anticlockwise shifted parasitically coupled elements. Gain is improved from $6.6 \mathrm{dBi}$ for reference patch to $8.33 \mathrm{dBi}$ for multiresonators gap coupled antenna.

\section{s}

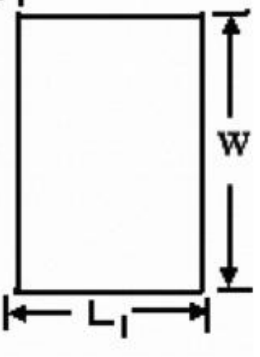

higher gain with three rectangular patches stacked on a single fed patch yielded bandwidth of $830 \mathrm{MHz}(25.7 \%)$ with more than $10 \mathrm{~dB}$ gain.

and analyzed [13]. And geometry is shown in figure (7). The impedance bandwidth of $12.7 \%$ i.e. $365 \mathrm{MHz}$ at center 
frequency $2879 \mathrm{MHz}$ is obtained with $10 \mathrm{~dB}$ return loss. When one patch without any coupling (i.e. direct and parasitic coupling) is analyzed, impedance bandwidth of $54 \mathrm{MHz}$ (i.e. $2 \%$ ) is obtained at center frequency at $2710 \mathrm{MHz}$. When both cases are compared (i.e. $12 \%$ Vs $2 \%$ ) then the impedance bandwidth of about 6.35 times is obtained for proposed antenna. Use of additional resonators patches either directly or gap coupled to the radiating patch will lead to a broadband configuration of microstrip antenna. Though the size of resulting antenna is bigger but the resulting bandwidth is much more than that of a single patch microstrip antenna.

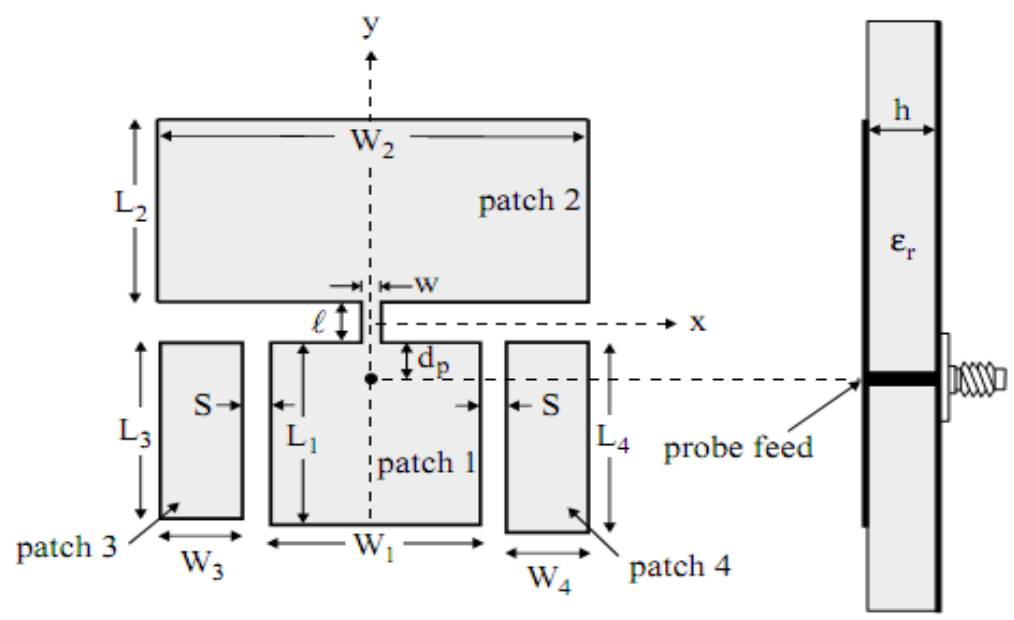

Fig 7: Proposed geometry of multi-resonator patch antenna [13].

\subsection{Multilayered configurations of Broadband Microstrip Patch Antenna}

In multilayered configuration patches are placed over different dielectric substrates and they are stacked on each other. Based on the coupling mechanism, these configurations are of two types electromagnetically-coupled or aperture-coupled. Electromagnetic coupled microstrip antenna one or more patches are located on different dielectric layers. If twolayered configuration of broadband microstrip patch antenna is analyzed then any one of them may be fed and other is electromagnetically coupled. Patch dimensions and dielectric constant of substrate may be different where as resonant frequency is closer to each other for obtaining broad bandwidth [14]. In aperture coupling, the field is coupled from the microstrip feed line placed on the other side of ground plane to the radiating patch through an electrically small aperture/slot in the ground plane. Two different dielectric substrates could be chosen one for the patch and other for feed line [14].

Very high bandwidth can be generated by using multilayered configurations. Near about $70 \%$ bandwidth can be generated using multilayered configuration. Microstrip line feed electromagnetically coupled microstrip antenna [15] is a method of exciting the patch. One proposed design of electromagnetically coupled microstrip antenna is shown in figure (8). This technique has the advantage that the dielectric constant of substrate used for microstrip feed line is high and it is thin so that radiation from feed line should be minimized, whereas the dielectric constant of substrate used for radiating patch is low and it is thick which improves the bandwidth of antenna [15].

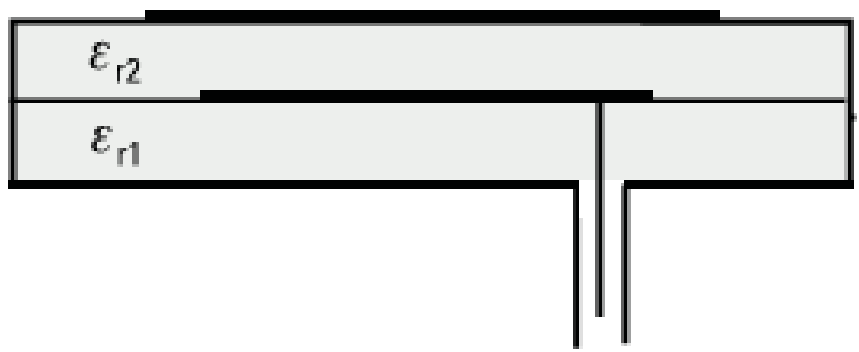

Fig 8: Proposed design of electromagnetically coupled microstrip antenna [14].

Aperture coupled microstrip patch antenna as shown in figure (9) is also an indirect technique of exciting patch. In this configuration feed line is on lower side of ground plane which is having an aperture/slot, and is made up of substrate with high dielectric constant to reduce radiation losses. Whereas the top patch is made up of thick substrate with lower dielectric constant.
Main disadvantage of this multilayered microstrip configuration is its increased height which is not desirable in miniature devices and in aperture coupling backward radiation is major problem [14]. 


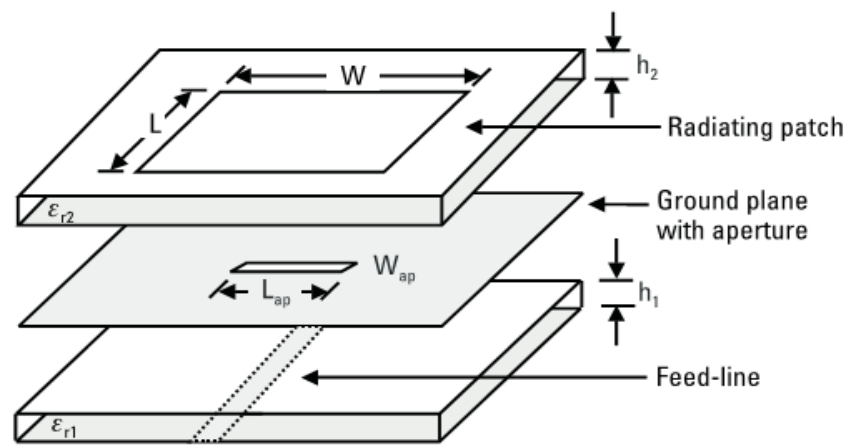

(c)

Fig 9: Proposed design of aperture coupled microstrip patch antenna [14].

\subsection{Stacked Multiresonator microstrip patch antenna}

In this configuration multiresonator and stacked configurations are combined to provide broadband microstrip patch antenna. A design of dual-frequency broadband-stacked microstrip antenna using a reactive loading and a fractalshaped radiating edge [16], shown in figure (10) is proposed.
In this proposal to obtain dual-frequency operation antenna is loaded with stub for changing frequency and then broader bandwidth is achieved by using stacked parasitic technique. The central frequencies of the first and second operating bands are 1.524 and $2.159 \mathrm{GHz}$, bandwidth enhancement factor achieved is 22.3 in the first band and 18.7 in the second band and bandwidth achieved is $12 \%$ and $5 \%$ resp. [16].
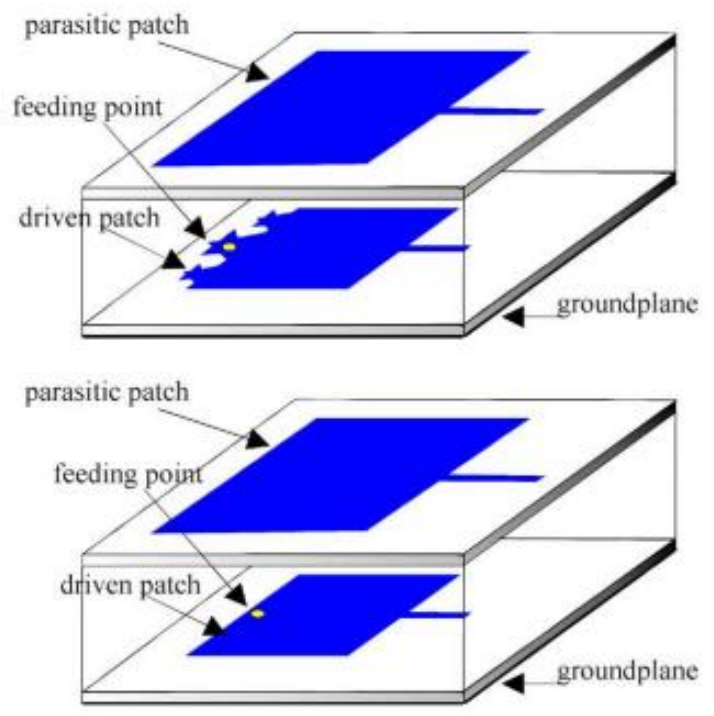

Fig 10: Stacked multiresonator antenna using a reactive loading and a fractal-shaped radiating edge [16].

Another broadband design using stacked multiresonator configuration is gap-coupled planar multiresonator and stacked configurations [12]; shown in figure (6) are combined to obtain wide bandwidth with higher gain with three rectangular patches stacked on a single fed patch yielded bandwidth of $830 \mathrm{MHz}(25.7 \%)$ with more than $10 \mathrm{~dB}$ gain.

A proposed broadband design using stacked U-slot microstrip antenna incorporating E-shape and modified half-E shape radiating patches [17] are introduced. Maximum impedance bandwidth achieved is $60.2 \%$. Its figures are shown below in figure (11). Though size of stacked multiresonator microstrip patch antenna is more but it yields high bandwidth and high gain. 

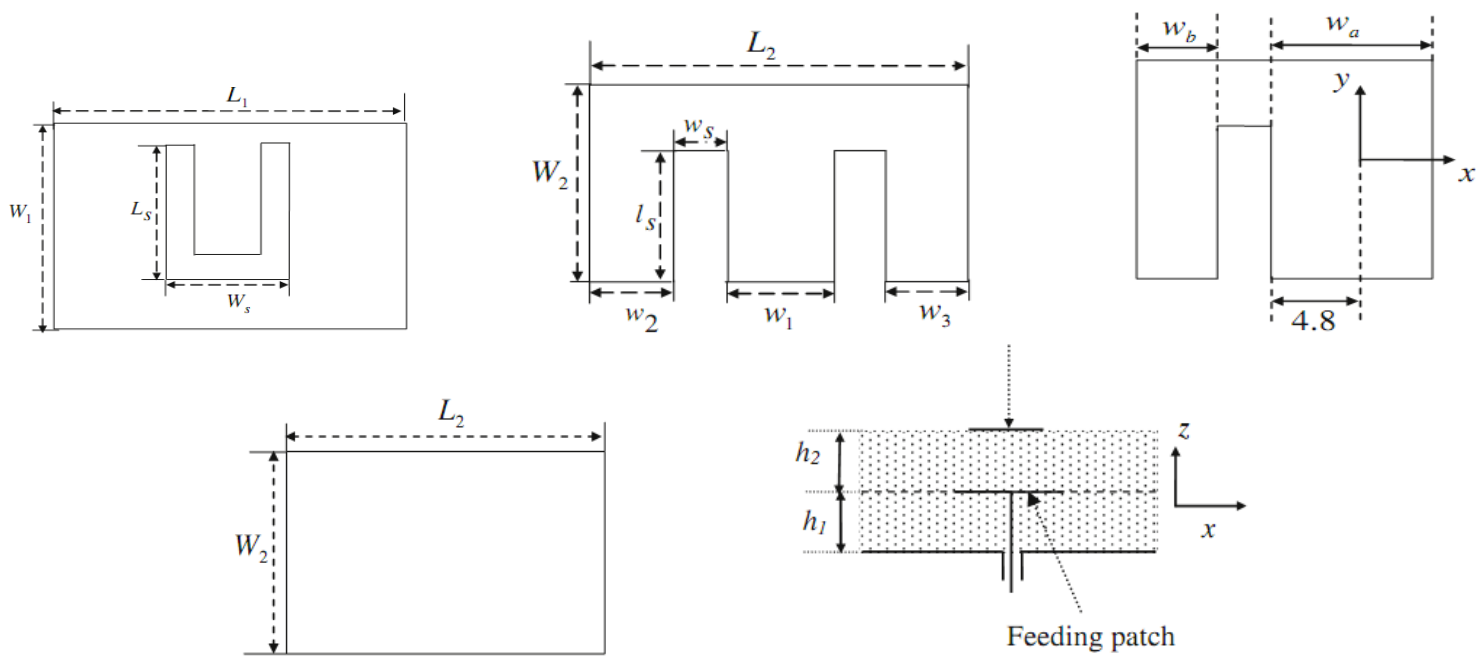

Fig 11: Designs of U-slot feeding patch, E-shaped radiating patch, modified half E-shape radiating patch, simple radiating patch and Side-view of stacked configuration [17].

\section{TABLE FOR THE COMPARATIVE ANALYSES OF BROADBAND TECHNIQUES}

\begin{tabular}{|c|c|c|c|}
\hline S. No. & Broadband Techniques & Configurations & Remarks \\
\hline \multirow{4}{*}{1.} & \multirow{4}{*}{ Modified Shape Patch } & Diamond shape slot patch[6] & $\begin{array}{l}\text { Bandwidth achieved is } 13.58 \% \text { when } \\
\text { compared with conventional circular patch. }\end{array}$ \\
\hline & & T-slot rectangular patch[7] & $\begin{array}{l}\text { Impedance Bandwidth of } 25.23 \% \text { with } \\
\text { average gain of } 7.43 \mathrm{dBi} \text { is obtained. }\end{array}$ \\
\hline & & $\begin{array}{l}\text { U-shaped slot with single-layer } \\
\text { single-patch[8] }\end{array}$ & $\begin{array}{l}\text { Air substrate of } 12 \mathrm{~mm} \text { is used to yield } \\
\text { bandwidth of } 27.5 \% \text {. }\end{array}$ \\
\hline & & E-H shaped patch[9] & Yielded bandwidth is about $27 \%$. \\
\hline \multirow{3}{*}{2.} & \multirow{3}{*}{ Multiresonator Technique } & $\begin{array}{l}\text { Shifted parasitically coupled } \\
\text { multiresonator[11] }\end{array}$ & $\begin{array}{l}\text { Improves the impedance bandwidth from } \\
65 \mathrm{MHz} \text { to } 251 \mathrm{MHz} \text { (about four times) } \\
\text { with minor variation of resonance } \\
\text { frequency from } 2.989 \mathrm{GHz} \text { of reference } \\
\text { patch to } 3.023 \mathrm{GHz} \text {. }\end{array}$ \\
\hline & & $\begin{array}{l}\text { Gap-coupled multiresonator and } \\
\text { stacked configuration[12] }\end{array}$ & $\begin{array}{l}\text { Yielded bandwidth of } 25.7 \% \text { with more } \\
\text { than } 10 \mathrm{~dB} \text { gain. }\end{array}$ \\
\hline & & $\begin{array}{l}\text { Directly coupled and parasitic } \\
\text { patches[13] }\end{array}$ & $\begin{array}{l}\text { Impedance bandwidth of } 12.7 \% \text { (365 } \\
\mathrm{MHz}) \text { is obtained, which is } 6.35 \text { times } \\
\text { when compared with the simple patch i.e. } \\
2 \%(54 \mathrm{MHz}) \text { at same center frequency of } \\
2879 \mathrm{MHz} \text {. }\end{array}$ \\
\hline 3. & Multilayered Technique & $\begin{array}{l}\text { Multilayered configuration of } \\
\text { patches[15] }\end{array}$ & $\begin{array}{l}\text { Nearly } 70 \% \text { of bandwidth can be generated } \\
\text { by using multilayered configuration of } \\
\text { radiating patches. }\end{array}$ \\
\hline \multirow{3}{*}{4.} & \multirow{3}{*}{ Stacked Multilayered Technique } & $\begin{array}{l}\text { Dual-frequency stacked patch } \\
\text { with reactive loading[16] }\end{array}$ & $\begin{array}{l}\text { Bandwidth enhancement factor is } 22.3 \text { and } \\
18.7 \text { for } 1.524 \mathrm{GHz} \text { and } 2.159 \mathrm{GHz} \text { resp. } \\
\text { which is further } 12 \% \text { and } 5 \% \text { for their } \\
\text { respective bands. }\end{array}$ \\
\hline & & $\begin{array}{l}\text { Gap-coupled } \\
\text { multiresonator and } \\
\text { configuration[12] }\end{array}$ & $\begin{array}{l}\text { Yielded bandwidth of } 25.7 \% \text { with more } \\
\text { than } 10 \mathrm{~dB} \text { gain }\end{array}$ \\
\hline & & $\begin{array}{l}\text { Stacked U-slot microstrip } \\
\text { antenna incorporating E-shape } \\
\text { and modified half-E shape } \\
\text { radiating patch configuration[17] }\end{array}$ & $\begin{array}{l}\text { Maximum impedance bandwidth of } 60.2 \% \\
\text { can be obtained. }\end{array}$ \\
\hline
\end{tabular}




\section{CONCLUSION}

Narrow bandwidth of microstrip patch antenna is its major limitation; to improve/enhance bandwidth many bandwidth enhancement techniques are used. This paper shows the review and survey of various such techniques used for enhancing the bandwidth of microstrip patch antenna. Out of all techniques specified above in this paper Multilayered Technique and Stacked Multilayered Technique yield maximum bandwidth.

\section{REFERENCE}

[1]. Wikipedia, "http://en.wikipedia.org/wiki/Microstrip antenna Dated: $05 / 11 / 2012$ at $12: 12 \mathrm{AM}$

[2]. Kin-Lu Wong, "Compact and Broadband Microstrip Antennas", John Wiley \& Sons, page number: 12-14, ISBNs: 0-471-41717-3, 2002.

[3]. Kin-Lu Wong, "Compact and Broadband Microstrip Antennas", Copyright (c) John Wiley \& Sons, page number: 232-273, ISBNs: 0-471-41717-3, 2002.

[4]. David Sanchez-Hernandez and Ian D.Robertson, "A Survey of Broadband Microstrip Patch Antennas", Microwave Journal, page number: 1-10, Sept.1996.

[5]. Ramesh Garg, Parkash Bhartia, Inder Bahl and Apisak Ittipiboon, "Microstrip antenna design handbook", Artech House Antenna and Propagation Library, page number: 538, ISBN 0-89006-513-6, 2001.

[6]. Garima, D. Bhatnagar, J.S. Saini, V.K. Saxena and L.M. Joshi, "Design of broadband circular patch microstrip antenna with Diamond shape slot", Indian Journal of Radio and Space Physics Vol. 40, page number: 275-281, Oct. 2011.

[7]. Lolit Kumar Singh, Bhaskar Gupta and Partha P. Sarkar, "T-slot Broadband Rectangular Patch Antenna", International Journal of Electronic and Electrical Engineering Vol. 4, page number: 43-47, ISSN 0974$2174,2011$.

[8]. T. Huynh and K. F. Lee, "Single-layer single-patch wideband microstrip antenna", Electron. Lett. 31, page number: 1310-1311, Aug. 3, 1995.
[9]. Mohammad Tariqul Islam, Mohammed Nazmus Shakib and et al., "Modified E-H Shaped Microstrip Antenna for wireless Systems", IEEE International Conference on Networking, Proceedings, ISBN 978-1-4244-3492-3, page number: 794-796, Japan, March 26-29, 2009.

[10].Girish Kumar and K.P. Ray, "Broadband microstrip antennas", Artech House antennas and propagation library, page number: 14, 89-90, ISBN 1-58053-244-6, 2003.

[11].K. Chattopadhyay, S.K. Parui, S. Das and S.R. Bhadra Chaudhuri, "Bandwidth Enhancement of Microstrip Antennas Using Shifted Parasitically Coupled Planar Multiresonators", Applied Electromagnetics Conference (AEMC), IEEE, ISBN 978-1-4244-4819-7, 2009.

[12].Girish Kumar and K.P. Ray, "Stacked gap-coupled multi-resonator rectangular microstrip antennas", Antennas and Propagation Society International Symposium, IEEE Vol. 3, ISBN 0-7803-7070-8, page number: $514-517$, Aug. 7, 2002

[13].C. K. Wu and K. L. Wong, "Broadband microstrip antenna with directly coupled and gap-coupled parasitic patches", Microwave Opt. Technol. Lett. 22, 348-349, Sept. 5, 1999

[14].Girish Kumar and K.P. Ray, "Broadband microstrip antennas", Artech House antennas and propagation library, page number: 15-17, ISBN 1-58053-244-6, 2003.

[15].Girish Kumar and K.P. Ray, "Broadband microstrip antennas", Artech House antennas and propagation library, page number: 132-138, ISBN 1-58053-244-6, 2003.

[16].J. Anguera, C. Puente and et al., "Dual-Frequency Broadband-Stacked Microstrip Antenna Using a Reactive Loading and a Fractal-Shaped Radiating Edge", IEEE Antenna and Wireless Propagation Letter, VOL. 6, page number: 309-312, ISSN 1536-1225, 2007.

[17].M. A. Matin, B. S. Sharif and C. C. Tsimenidis, "Broadband Stacked Microstrip Antennas with Different Radiating Patch", Springer Science+Business MediaWireless Pers Commun, page number: 637-648, $11277-$ 009-9836-7, Oct. 9, 2009 